\title{
INFLUENNCIA DO CARVÃO NA ALIMENTAÇÃO DAS AVES
}

\author{
A. Di Paravicinl Torres \\ Prot. de Zootecnia Geral \\ Alvaro Piedade \\ 2.0 assistente de Zootecnia Geral \\ Seção de Avicultura Cunicultura
}

INDICE

\begin{tabular}{|c|c|}
\hline Introdução & \\
\hline Material e & Métodos \\
\hline Conclusőes & finais .. \\
\hline Resumo & \\
\hline Abstract & \\
\hline Literatura & \\
\hline
\end{tabular}




\section{INTRODUÇÃO}

A utilizaçăo do carvão na alimentaçăo das aves domésticas é, a nosso vêr, uma prática rotineira, quase generalizada. Dela abusam os fabricantes de ração, pois a adição de 5 a $6 \%$ de pó de carvão, obtido das varreduras das carvoarias a baixo preço, contribul para economizar outros tantos por cento de alimentos de custo elevado.

Outros acreditam simplesmente nos possiveis benefícios do carvăo. A explicaçáo mais completa dessas vantagens, encontramo-las em MELO (1).

"A junção do carvão de madeira na alimentação das aves é muito aconselhável. de de explicaçóes dadas por diferentes autores sôbre a ação que êste produto tem sôbre o tubo digestivo.

"Segundo uns, essa ação favorece a engorda dos animais, sem que, no entantó, seja dada qualquer explicação do modo como se dá tal fato. Para outros o carvão de madeira é um sucedaneo do șal nas raçōes, isto é, funciona como um excitante do apetite. Outros ainda, julgam-no idéntico ao sal de cozinha, acrescentando que desinfeta também o intestino das aves.

"Mas, na verdade, apenas o modo de fabricação e a composiçăo do carvăo de madeira podem explicar de um modo racional os efeitos que exerce.

"Como é sabido, o carvão de madeira obtém-se pela combustăo lenta, em presença de uma limitada quantidade de ar, de pequenos fragmentos de ramos, reunidos em montes, que depois se cobrem com terra ou barro. Essa combustão, numa atmosfera em que falta o oxigênio, é incompleta; as matérias volátels existentes na madeira ou produzidas pela elevação da temperatura evolam-se com o fumo; ficam apenas no carvão a maioria do carbono existente no lenho, as substâncias minerais e ainda alguns produtos orgânicos não voláteis. Entre estes, há alguns fenois e derivados, cujas propriedades antiséticas são indiscutiveis.

"O carvão de madeira conserva a forma e quase o volume da madeira de que proveio; pela perda de várias substancias, torná-se poroso, o que lhe dá um grande poder absorvente para os gases, como se verifica pelos números seguintes.

"Um volume de carvão de madeira pode absorver: 90 volumes de amoníaco; 55 volumes de ácido sulfúrico; 55 volumes de ácido carbonico, etc.. Estas propriedades físicas e aquelas, de desinfetante, tornam bem clara a ação que o carvão de madeira exerce no tubo digestivo: pela sua porosidade absorve o.9 gases produzidos pelas fermentações intestinais: amoníaco, ácl- 
do sulfúrico (?), etc.. Evita, consequentemente, o timpanismo, cujos efeitos săo sempre desastrosos.

"Por outra forma, os produtos derivados dos fenois, que contém, destroem germes e parasitas intestinais, cuja açăo é nefasta para a saude da ave pelas fermentaçós que geralmente ocasionam.

"Portanto a açăo do carvăo de madeira no Intestino dos animais, traduz-se por uma diminuiçăo de fermentaçరes e pela absorçăo de gases provenientes dessas fermentaçōes; e năo. delxa de ser benéfica esta açăo.

"Diz-se que o carvăo de madelra favorece a pastura das galinhas; so indiretamente o poderá fazer, pois concorre para lhes conservar a saude."

Até 0 inicio de nossas experiências, participávamos desses conceitos quase gerais, entretanto soubemos que o Instituto Biológico estava condenando o uso do carvăo nas raçóes das aves. Procurámos informar-nos a respeito em trabalho de REIS (2), chefe da Seç̧̃o de Ornitopatologia daquele Instituto, tendo encontrado o seguinte trecho: " um hábito muito generalizado adiclonar carváo vegetal a raçăo das aves, na proporçåo média de $\mathbf{2 0 \%}$. essa todavia uma prática que ná se justifica, pols náo acarreta nenhuma vantagem, podendo, ao contrário, contribuir para a inativaçăo ou destruiçăo de certas vitaminas existentes na raçăo". Até entåo nada sabiamos sobre isso, mas tínhamos lido alhures que o caolim, outro absorvente, ingerido com tiamina, tinha a propriedade de absorvê-la e que o carvăo, junto a certos medicamentos, inativa-os, isto é, absorve-os, impede a absorçăo intestinal. Assim, achamos razó́vel a asserçáo de REIS.

Examinando-se a literatura sobre o uso do carvăo nas raçōes, verifica-se que grande número de autores americanos. em trabalhos recentes, omitem completamente de suas obras a palavra "Charcoal". Outros, BARTHOLOMEU (3), MORAES (4), N.N. (5), COSTA F.o (6), SANTOS (7), CRESPO (8), SEQUEIRA (9), SMTTH (10), STEVENSON (11), ROBERTSON \& GUTTRIDGE (12), BIFDMA \& SEQUEIRA (13) limitam-so a recomendḱ-1o.

Como medicaçăo, ora da indigestăo ingluvial (inflamaçăo do papo), ora da diarréa das pintos, encontra apoio em RICE \& BOTSFORD (14), REIS (15), DURINGEN-(16) e PEARL \& Cols. (17). pste prefere para tal fím o carvăo misturado na farelada que em comedouros separados.

Há os que o recomendam para limpar e purificar ó intestino, em proporçóes variáveis de 0,5 a $5 \%$ na farelada, ou em 
comedouros separados, com o fim de limpar e purificar as vias digestivas, conservando as aves em boas condiçס̃es: LEWIS (18), DURINGEN (16), LAHAYE \& MARCQ (19), TORRES (20) e BRILLAT (21).

Finalmente, há os que por qualquer forma duvidam do benefício do carváo como alimento. Para as nossas investigaçoes sáo essas as opinióes mais interessantes e porisso mesmo deverăo ser reproduzidas.

Falando sobre os alimentos minerais, HOLST e Cols. (22) acham que o carvăo deveria ser mencionado entre éles, pois é frequentemente recomendado e usado como um suplemento das raçōes de aves, porém declaram que náo há nenhuma evidencia experimental favorável para mostrar $o$ beneficio da alimentaçăo com carvão; de outro lado nada existe que demonstre sua nocividade. Mesmo quando presente, 0 poder absorvente deve ser de valor discutivel. O carvåo para as aves deve se: considerado como uma despesa inútil, como foi abandonado da dieta humana, onde era antigamente recomendado.

Sob o título de alimentos de valor discutível, JULL (23) declara que embora seja o carváo um bom absorvente para os gases, ainda náo fol comprovada sua utilidade na raçăo para qualquer finalidade.

Para WATTE (24), o carvăo é, ou melhor, fol muito recomendado como um corretivo para ser deixado permanentemente à disposiçáo das aves. Sua açăo é inteiramente mecánica e consiste na absorçăo dos gases resultantes de desordens digestivas. algumas vezes fornecido em comedouros e outras misturado na farelada. Conquanto o carvăo năo seja nocivo, e, provàvelmente benéfico em alguns casos, grande número de criadores năo o consideram essencial no seu trabalho de racionamento.

Mesmo na alimentaçăo dos suinos, MORRISON (25) acha deșnecessária a adiçăo do carvăo à raçăo, quando os sais essenciais eståo presentes.

Finalmente LAMON \& LEE (26), assim se expressam: "O carvăo é geralmente fornecido às aves de tódas as idades, podendo ser colocado em comedouros próprios ou misturado na raçăo. Usa-se geralmente 0,5 a $1 \%$ na mistura de farelada. $O$ carvåo é também usado por alguns cevadores de galinhas, embora outros năo o considerem essencial ou com algum valor. Ele provàvelmente auxilia na correçăo das perturbaçóes digestivas e conserva as aves com boa saúde pela sua capacidade de absorver gases. Há alguma diferença de opiniăo quanto ao seu valor para qualquer espécie de aves e muitos avicultores náo 
io usam de maneira alguma, mas, como a quantidade de carvão consumido pelas aves ou galinhas ou pintos é muito pequena, talvez seja o ingrediente menos valioso da ração. Alguns avicultores fazem seu próprio carvão queimando pequenos pedaços de madeira dura para ésse fim. A maioria das misturas de farelos comerciais contém uma pequena porcentagem de carvåo".

Assim posta a questão resolveu, um de nós (PIEDADE) investigar o assunto em pintos, pois vinhamos constatando que o crescimento não correspondia à ração fornecida. As pesagens e análises dos resultados foram feitas pelo mesmo, que, retirando-se da Seção, deixou de fazer a redação, ora feita por TORRES.

\section{MATERIAL E MÉTODOS}

Dois lotes de 50 pintos cada, da mesma raça e ninhada, sem distinçáo de sexo, foram organizados e colocados no "pinteiro" nas mesmas condiçōes ordinárias de criação, salvo que. um - Lote A, recebia na ração de farelada $5 \%$ de carvăo de madeira, moido. As aves recebiam suficiente quantidade de verduras e dispunham de um solário para suprir a falta possivel de vitamina $D$ na ração.

Os dois lotes A e B eram suficientemente homogéneos, pois as médias eram 99,720 grs. $\pm 1,72$ e $100,040 \pm 0,302$, respectivamente, sendo o t-test da diferença igual a 0,09 .

$\mathrm{Na}$ segunda pesagem, realizada no dia 16-11 (10 dias após o início da experiencia) já se constatava uma diferença de mais de $10 \%$ em péso a favor dos pintos sem carváo (Lote B), porém essa diferença não chegava a ser suficientemente significativa - T-test $=2,02$. A mortalidade mostrou-se mais elevada nos pintos sem carvão: 8 para 1 apenas no regime de carvăo. A aparência geral dos pintos sem carvão era melhor.

$\mathrm{Na}$ terceira pesagem, realizada em 1-12 (vinte e cinco dias após o início da experiência) havia 42 pintos no lote com carvão e 36 no lote sem carvão, pesando respectivamente uma média de 174,9 e 262,2 gramas. A diferença estabelecida pelo t-test $=6,10$ era bastante significativa, mostrando a superioridade da ração sem carvão, quer no aumento de pêso, quer na aparencia geral.

A mortalidade no fim da experiéncia foi, como se ve, de $16 \%$ na ração com carvão e $28 \%$ na sem carvão. possível pois que o carvão tenha aos pintos mais fracos, doentios, permitido uma maior sobrevivencia.

Se admitirmos que os 6 pintos menos pesados do Lote A 
tivessem morrido e ficassem 36 como no lote $B$, a média dos restantes elevar-se-ia apenas a 182,2 grs., 80 grs. ou $28,4 \%$ menos que os do lote $B$.

\section{CONCLUSOES FINAIS}

A experiencia năo deixa dúvida que os pintos submetidos a uma raçăo sem carvăo aproveitam melhor os alimentos.

Fica porém a dúvida se o carvão protege os pintos mais fracos de uma maior mortalidade, pois houve $12 \%$ menos mortalidade nos pintos submetidos ao regime de carvăo. Se tal for comprovado em novas experiências, o uso do carvão seria recomendável e restrito aos pintos mais fracos, de aparência doentia, que costumam ser separados dos demais como "refugo". Nesse sentido pretendemos conduzir nassas observaçðes futuras.

\section{RESUMO}

Dois lotes de 50 pintos foram submetidos, durante 25 dias, ao mesmo regime, salvo que um (A) recebeu $5 \%$ de carvåo na farelada e outro (B) năo.

No fím da experiência, a média de péso do lote A era 174,9 grs. e a do lote $B, 262,2$; a diferença é significativamente favorável ao lote $B$ em relação ao pêso, contudo a mortalidade fol maior $(12 \%)$ no lote que năo recebeu carvăo. A aparência geral dos pintos do lote $B$ era muito melhor.

Os AA. concluem que o carvăo năo deve ser usado como alimento. provàvelmente por absorver muitas subtancias útels à nutriçăo, possivelmente vitaminas e amino-ácidos, mas sim para os pintos que se atrazam no crescimento devido a perturbações do aparêlho digestivo, como um medicamento. Esta última ronclusăo depende de ulterior comprovação, pois a maior mortalidade constatada no lote sem carvão pode ser devida ao acaso, simplesmente.

\section{ABSTRACT}

Two groups of 50 chicks each ( 100 grs. initial weight) were put into competition during 25 days to see whether or not the addition of $5 \%$ of charcoal in the feeds is benefical.

At the end of the experiment, the average weight of the group which received charcoal was 174,9 grs., and of the control 262,2 grs., revealing the chicks of the latter better general appearance. 
This result shows the detrimental effect of the charcoal, but since mortality was greater in the group fed without it, a benefical effect of the charcoal in protecting woaker chicks against mortality may be admitted. This contentation, however, needs comprobations.

\section{LITERATURA}

1 - MELO, M. de, 1946 - O Carvăo de Madeira na Alimentaça das Aves, in "O Campo", n. 122, pp. 45, Rio.

2 - REIS, J., 1944 - Criaçăo de Galinhas, ed. Melh., S. Paulo.

3 - BARTHOLOMEU, A., s/d - Conjunt ode Liçбes sobre a Criaçåo de Galinhas, etc.. S. Paulo.

4 - MORAES, F. F. de, 1916 - Compendio de Avicultura, s. Paulo.

5 - Anonimo, 1932 - Avicultura, La Alimentacion de la Gallina, Cart. n. 8, D. Agr. e Gan. Min. Fom. Perú.

6 - COSTA F.o, J. W., 1934 - A alimentaga das Aves e os Fatores que influem na Soluçáo do Problema, Sec. da Agr. S. Paulo.

7 - SANTOS, E., s/d - Avicultura, Fonte de Riqueza, Rio.

8 - CRESPO, R. J., 1927 - Apuntes de Avicultura, Madrid.

9 - SEQUeIRA, O. de, 1932 - Criaçáo de Pintos, S. Paulo.

10 - SMITH, A. C., 1936 - Poultry for Profit, Circ. 20, Agr. Ext. Div. Univ. of Minn. Minnesota.

11 - STEVEnsON, G. L., 1929 - Results of Poultry Feeding Experiments, P. Dp. Agr. Exp. St. South Dakota, st. Col. Brookings.

12 - ROBERTSON, G. e GUTTERIDGE, H. S., 1936 - Poultry Feeds and Feeding, Pulb. 541 - Farm's Bull. 20 - Dep. Agr. Canadá.

13 - BIEDMA, P. C. A SEQUEIRA, O. de, 1933 - 3.2 ed., 8. Paulo.

14 - RICE, J. E. e BOTSFORD, H. E., 1934 - Avicultura Prática, trad. da 2.a ed. em espanhol por J. M. Soller Cole, Barcelona.

15 - REJS, J., 1932 -- Moléstias das Aves Domésticas, S. Paulo.

16 - DURINGEN, B., 1931 -- Tratado de Avicultura, trad. 5.a ed. esp. de Martinez Amador, Barcelona. 
17 - PEARL, R., SURFACE, F. M.e CURTIS, M. R., 1923 - Diseases of Poultry, New York.

18 - LEWIS, H. R., 1933 - Production Poultry Husbandry 8.a ed. rev. - Chicago.

19 - LAHAYE, J. e MARCQ, J., 1933 - Traité Complet d'Aviculture - Gembloux.

20 - TORRES, S., 1936 - Alimentaçáo de Galinhas - Bol. D. N. P. A. - Rio.

21 - BRILLAT, A., s/d - Avicultura Industrial, Barcelona.

22 - HOLST, W. F. e NEWLON, W. E., 1935 - Poultry Feeding: Principles and Practice, Bul. 417, rev. por ALMQUIST, $H$. J. e JUKEES, T. H., Agr. Exp. St. Univ. of California, Berkeley.

23 - JULL, M. A., 1938 - Poultry Husbandry, 2.2 ed. 2.2 ImpNew York.

24 - WAITE, R. H., 1929 - Poultry Science and Practice, 1.2 ed. 4.a impr., New York.

25 - MORRISON, F. B., 1943 - Feeds and Feeding, 20.a ed. 10 impr.. Itaca.

26 - LAMON, H. M., e LEE, A. R., 1929 - Poultry Feeds and Feeding, New York. 